\title{
Clinical and Biochemical Effects of Recombinant Human Granulocyte Colony-Stimulating Factor on the Prognosis of Preterm Infants with Early Onset Neonatal Sepsis
}

\author{
Reza Saeidi ${ }^{1}$, Hossein Akhavan ${ }^{1}$, Jalil Tavakkolafshari ${ }^{2}$ and Abbas Shapouri-Moghaddam ${ }^{3, *}$ \\ ${ }^{1}$ Neonatal Research Center, Imam Reza Hospital, Faculty of Medicine, Mashhad University of Medical Sciences, Mashhad, Iran \\ ${ }^{2}$ Immunology Research Center, Faculty of Medicine, Mashhad University of Medical Sciences, Mashhad, Iran \\ ${ }^{3}$ Department of Immunology, Avicenna Research Institute, Mashhad University of Medical Sciences, Mashhad, Iran \\ "Corresponding author: Department of Immunology, Avicenna Research Institute, Mashhad University of Medical Sciences, P.O. Box: 91778-99191, Mashhad, Iran. Tel: \\ +98-5137112471, Fax: +98-5137112596, Email: shapouri9153152927@gmail.com
}

Received 2018 February 22; Revised 2018 August 14; Accepted 2018 October 26.

\begin{abstract}
Background: A double-blind, placebo-controlled randomized trial was designed to investigate the effects of recombinant human granulocyte colony-stimulating factor (rhG-CSF) on the prognosis of preterm infants with early onset neonatal sepsis (EONS).

Methods: Fifty preterm infants were selected from the neonatal intensive care unit (NICU) of Qaem Hospital, Mashhad, Iran in 2011. They were randomized to rhG-CSF (intervention group, $n=25$ ) or identical placebo (control group, $n=25$ ) for 3 days. The following blood parameters were measured: White blood cells count (WBC), absolute neutrophil count (ANC), serum level of highsensitivity C-reactive protein (hs-CRP), and the ratio of immature to total neutrophils. In addition, the mortality rate, adverse effects, and duration of hospital stay were evaluated as clinical parameters.

Results: At baseline, both groups were not significantly different $(\mathrm{P}>0.05)$ except for the hs-CRP level $(\mathrm{P}=0.024)$ and hypoglycemia $(\mathrm{P}=0.001)$. Compared with the controls, significant improvements were only observed in WBC $(\mathrm{P}=0.001)$ and ANC $(\mathrm{P}=0.010)$ of the intervention group. The mean difference in the WBC, ANC, hs-CRP level, and the ratio of immature to total neutrophils between the baseline and 3-day post-treatment values was higher in the controls than the intervention group. More than $90 \%$ of the patients exposed to either rhG-CSF or placebo hospitalized for over 72 hours and no significant difference was found between them $(\mathrm{P}=$ 0.946). In each group, a decease was recorded (4.0\%) during the hospitalization.

Conclusions: The rhG-CSF administration could effectively improve WBC and ANC. No significant changes were observed in mortality rate, adverse effects, and hospital stay after the treatment.
\end{abstract}

Keywords: Recombinant Human Granulocyte Colony Stimulating Factor, Early Onset Neonatal Sepsis, Preterm Infants, Randomized Controlled Trial

\section{Background}

Neonatal sepsis is referred to as a medical condition in which a blood infection occurs in infants below 90 days old. It has been reported that $2 \%$ of intrauterine fetus and $10 \%$ of neonates develop neonatal sepsis during the first month of birth (1). Globally, sepsis is recognized as one of the most common causes of neonatal deaths $(2,3)$. It also contributes to mounted medical costs, prolonged hospital stay, and potentially poor long-term neurodevelopmental outcomes (4). Early-onset neonatal sepsis (EONS) is known as a sepsis developing in the first seven days of life (5). Majority of infants show symptoms within 24 hours of birth (6). EONS is mainly generated by pathogenic bacteria transmitted vertically from mother to infant prior to or during delivery through the birth canal $(7,8)$. The incidence of EONS is different between countries and research centers (9). It has been reported that $0.5 \%$ of infants admitted to Canadian neonatal intensive care units (ICUs) presented with EONS (10). Recent evidence from the USA has shown the overall incidence and case fatality rate of EONS was approximately 0.77 cases per 1000 live births and $10.9 \%$, respectively (11). Invasive group B streptococcus (GBS) infection in neonates constitutes the most common cause of EONS at increasing morbidity and mortality risk (12). Gestational age (GA) has a lowering effect on the incidence and case fatality rates. Women with preterm birth less than 37week-GA are at risk for infection and intrapartum antibiotic prophylaxis should be administered, especially when GBS colonization remains suspected $(5,13)$. 
Clinical presentation of EONS among preterm infants often includes apnea, bradycardia, and cyanosis (65.8\%) (14). Moreover, high incidence of poor activity, probably lethargy (48.7\%), and respiratory effort (43.0\%) were found in these infants (14). Several variables, including white blood cells count (WBC) and C-reactive protein (CRP) are used to diagnose the early bacterial infection in neonates; despite the specificity of CRP, this serological marker is less sensitive in early stages of neonatal sepsis (15-20). Recently, inflammatory cytokines such as interleukin 6 (IL-6), interleukin 8 (IL-8), granulocyte colony-stimulating factor (G$\mathrm{CSF}$ ), and tumor necrosis factor (TNF- $\alpha$ ) were investigated as effective markers for this purpose in both infants and adults (21-25).

G-CSF is a prominent cytokine improving the function and growth of neutrophils. Despite the early evidence indicating the positive contribution of G-CSF to the treatment of EONS (26-28), there are controversies still exist on its application in infants, so further studies are required in either clinical or non-clinical (in vitro and in vivo) settings (29-32). Considering the high incidence of sepsis in preterm infants and its subsequent morbidity and mortality $(33,34)$, the objective of the present study was to evaluate the efficacy of the recombinant human G-CSF (rhG-CSF) administration on blood parameters (WBC, ANC, hs-CRP level and the ratio of immature to total neutrophils), and clinical parameters (mortality rate, adverse effects and duration of hospital stay) in preterm infants with EONS hospitalized at the NICU of Qaem Hospital in Mashhad, Iran. To the best of our knowledge, there was no report on the rhG-CSF administration in preterm infants with EONS to date and this is the first clinical trial in Iran considering the treatment of EONS preterm infants with rhG-CSF.

\section{Methods}

This randomized controlled trial was designed to investigate the impact of rhG-CSF on preterm neonates with EONS within a period of three days. This interventional study received ethical approval from Medical Research Ethics Committee, Mashhad University of Medical Sciences (Ethical code: IR.MUMS.REC.1389.100). The CONSORT guidelines were adopted to design the present study, as well.

A total of 50 subjects were selected in 2011 from preterm infants who were admitted to the NICU of Qaem Hospital, Mashhad, Iran. To detect an increased effect on WBC over time (at least 2-fold at day 1) based on the study by Kocherlakota and La Gamma (26), with desired power of $80 \%$ and type one error of $5 \%$, the sample size was calculated 25, thus this trial included a total sample size of 50 participants. The written informed consents were obtained from all their parents or guardians, as well.
The clinical criteria of sepsis included temperature instability that was not justified by the effects of the environment $\left(<36^{\circ} \mathrm{C}\right.$ or $\left.>37.8^{\circ} \mathrm{C}\right)$, respiratory signs (gagging, apnea, cyanosis, tachypnea, and respiratory distress), cardiovascular signs (systemic hypotension, capillary filling time above 3 seconds, and cold extremities), neurological signs (irritability, poor feeding, lethargy, reduction in neonatal reflexes, seizure, bombing fontanel, and hypotonia), gastrointestinal signs (nausea and vomiting, abdominal distention, hepatomegaly, and icterus), and miscellaneous signs (e.g., petechial, purpura, disseminated hemorrhage, and conjunctivitis). Additionally, the laboratory criteria of sepsis were the following: Neutropenia (less than $1500 / \mu \mathrm{L}$ ), immature/total neutrophil ratio $>20 \%$, and hypoglycemia (plasma glucose $<50 \mathrm{mg} / \mathrm{dL}$ ). Sepsis was diagnosed if the infant met at least two clinical signs and at least one laboratory test with a positive result.

Other factors along with the diagnosis of sepsis were considered as the inclusion criteria of the present study: (1) gestational age (GA) below 35 weeks; (2) birth weight less than $2000 \mathrm{~g}$; (3) the presence of bacteria in the blood culture and infection signs in the first 3 days of life verified early-onset neonatal sepsis; (4) clinical presentation of infection in the absence of positive blood culture verified clinical sepsis in preterm infants; (5) sufficient renal and liver functions, which no kidney failure or liver failure happened in this study, and the laboratory renal or liver function tests assessing the functioning of the kidneys or liver showed normal results. In this study, GA was estimated based on the first day of the last menstrual period (LMP), and first and second-trimester ultrasound examinations.

Those patients with APGAR score less than five at five minutes, major congenital anomaly, severe birth asphyxia (hypoxic-ischemic encephalopathy), maternal severe preeclampsia unresponsive to medical therapy, systemic hypotension or metabolic disorders, absolute neutrophil count (ANC) greater than $6000 / \mu \mathrm{L}$ (35), and severe lesions like intraventricular hemorrhage with grade III and IV were excluded from the initial enrollment. The initial examinations were conducted by a neonatologist. Thereafter, patients' medical history was reviewed. The studied participants underwent baseline tests by means of a demographic questionnaire as well as biochemical analysis before the start of the intervention.

Using simple random allocation, these patients were equally categorized into two groups: Intervention $(n=25$; $10 \mu \mathrm{g} / \mathrm{kg} /$ day of rhG-CSF in dextrose $5 \%$ over $20-40 \mathrm{~min}$ utes for three consecutive days, intravenous infusions) and control ( $n=25$; an equivalent volume of dextrose $5 \%$ as placebo, intravenous infusions) groups. A nurse who was blind to the study was requested to dispense the medicine amongst the patients. All infants also received routine 
sepsis care, including antibiotics, inotropes, supplemental oxygen, and so on. Owing to the small sample size in the present trial, randomization was carried out through random number tables. The neonatologist and research investigator were blind to the group allocation and related treatment until the end of the study.

The following blood parameters were measured: WBC, ANC, serum level of hs-CRP, and the ratio of immature to total neutrophils. In addition, mortality rate and duration of hospital stay were evaluated as clinical measures. The laboratory tests were conducted prior to and following the intervention. The baseline variables were measured by using a demographic questionnaire: GA, sex, and clinical signs, including fever, respiratory distress, renal failure, cardiac failure, central nervous system (CNS) symptoms, gastrointestinal symptoms, anemia, and hypoglycemia. WBC counts were also performed through a hemocytometer. ANC was measured by examining the blood smears by a light microscope at a magnification of $400 \times$. The serum high-sensitivity CRP (hs-CRP) was evaluated by using a sensitive CRP assay (Monobind, INC. Lake Forest, USA). Moreover, duration of hospital stay was recorded from the first day following admission to the day of hospital discharged (36). The neonatal hospital mortality rate refers to the number of deaths reported in hospitalized newborns over a given period expressed as a percentage (37).

Data were collected and imported to SPSS (version 19, Chicago, USA). A nurse who was blind to the study, clinical laboratory technician, and the statistician were aware of randomization codes. The investigator, as well as the neonatologist, did not have any direct contact with this nurse assigned to the study, clinical laboratory technician, and statistician. Statistical analysis was carried out in triplicated. Descriptive statistics (mean \pm standard deviation) were used to present the data. The normality of data was evaluated by Lilliefors corrected Kolmogorov-Smirnov test. Student's $t$ test or its non-parametric equivalent(Wilcoxon Mann-Whitney test) was performed for paired comparisons. Pearson's chi-squared test or the Fisher's exact test was used to comparing proportions between the study groups. A P $<0.05$ was considered statistically significant.

\section{Results}

Fifty participants were randomized into both intervention $(n=25)$ and control $(n=25)$ groups and completed the intervention of three-day-duration. All of them were younger than 5 days old at the admission. There was no significant difference in demographic parameters between two groups (GA, gender; $\mathrm{P}>0.05$ ) except for hypoglycemia $(\mathrm{P}=0.001)$.
Two infants in the control group did not have any clinical signs of sepsis. There was no sign of renal insufficiency among the studied infants. Additionally, 74\% were delivered by cesarean section. No significant difference was found in the two types of delivery between the two groups $(\mathrm{P}=0.747)$. The average birth weight was $1500 \pm 499 \mathrm{~g}$ for all infants. There were no significant disparities in terms of height, weight, and head circumference between the two $(\mathrm{P}>0.05)$. A total of 14 urine samples was obtained from the intervention $(\mathrm{n}=4)$ and control $(\mathrm{n}=10)$ groups; it was found that all the cultures were negative. Similarly, in ten (intervention group, $\mathrm{n}=5$; control group, $\mathrm{n}=5$ ) cerebrospinal fluid samples, all the cultures appeared negative. On the other hand, the two groups did not significantly differ in the serum levels of sodium, potassium, urea, creatinine, bilirubin (total and direct) along with a partial thromboplastin time, prothrombin time, and international normalized ratio (data not shown) $(\mathrm{P}>0.05)$.

The findings of the blood analysis are presented in Table 2 . At baseline, both groups were statistically similar in WBC counts $(P=0.352)$, the ratio of immature/total neutrophils $(\mathrm{P}=0.993)$, and ANC $(\mathrm{P}=0.148)$. There was only a considerable difference in the hs-CRP level $(\mathrm{P}=0.024)$; the intervention group $(4.24 \pm 7.60 \mathrm{mg} / \mathrm{L})$ had markedly higher levels of hs-CRP than the control group (1.72 \pm 2.17 $\mathrm{mg} / \mathrm{L})$.

Data were compared between the two groups following a three-day-intervention (Table 2). Substantial differences were observed in the WBC $(\mathrm{P}=0.001)$ and ANC $(\mathrm{P}=$ 0.010). It was found that the utility of rhG-CSF notably increased the WBC $\left(13233.33 \pm 8244.03 \mathrm{~mL}^{-1}\right.$ vs. $7400.00 \pm$ $\left.6766.03 \mathrm{~mL}^{-1}\right)$ and ANC (6952.08 $\pm 5518.79 \mathrm{~mL}^{-1}$ vs. 2984.48 $\left.\pm 3158.71 \mathrm{~mL}^{-1}\right)$ in the intervention group as compared with the control group. The mean difference in the WBC between the baseline and 3-day post-treatment values was considerably higher in the controls than the intervention group $(P=0.016)$. Likewise, the mean difference in the ANC between the baseline and 3-day post-treatment values was greater in the controls than the intervention group; however, It was not statistically significant $(P=0.261)$. There was a slight increase in the serum hs-CRP level of the intervention group $(6.98 \pm 7.43 \mathrm{mg} / \mathrm{L})$; however, it was not statistically significant $(\mathrm{P}=0.105)$ in comparison to the control group $(5.77 \pm 9.16 \mathrm{mg} / \mathrm{L})$. Similarly, the mean difference in the hs-CRP level between the baseline and 3day post-treatment values was higher in the controls than the intervention group, however, It was not statistically significant $(\mathrm{P}=0.606)$. The ratio of immature/total neutrophils almost remained unchanged between the groups $(\mathrm{P}=0.345)$. The mean difference in the ratio of immature/total neutrophils between the baseline and 3-day posttreatment values was higher in the controls than the inter- 


\begin{tabular}{|c|c|c|c|}
\hline \multirow{2}{*}{ Characteristics } & \multicolumn{2}{|c|}{ Groups } & \multirow{2}{*}{ P Value } \\
\hline & Intervention $(n=25)$ & Control $(n=25)$ & \\
\hline \multicolumn{4}{|l|}{ GA, Mean \pm SD } \\
\hline LMP & $31.6 \pm 1.5$ & $31.4 \pm 2.2$ & $0.906^{\mathrm{a}}$ \\
\hline NBS & $32.1 \pm 1.5$ & $32.4 \pm 1.7$ & $0.375^{\mathrm{a}}$ \\
\hline Male, No. (\%) & $17(68)$ & $18(72)$ & $0.762^{\mathrm{b}}$ \\
\hline \multicolumn{4}{|l|}{ Clinical signs, No. (\%) } \\
\hline Fever & $0(0)$ & $1(4)$ & $0.999^{c}$ \\
\hline Respiratory distress & $23(92)$ & $25(100)$ & $0.490^{\mathrm{c}}$ \\
\hline Cardiac failure & $2(8)$ & $7(28)$ & $0.138^{\mathrm{c}}$ \\
\hline CNS symptoms & $22(88)$ & $24(96)$ & $0.609^{c}$ \\
\hline Gastrointestinal symptoms & $0(0)$ & $4(16)$ & $0.110^{c}$ \\
\hline Anemia & $0(0)$ & $1(4)$ & $0.999^{c}$ \\
\hline Hypoglycemia & $10(40)$ & $0(0)$ & $0.001^{\mathrm{c}}$ \\
\hline
\end{tabular}

Abbreviations: CNS, central nervous system; GA, gestational age; LMP, last menstrual period; NBS, new Ballard score.

${ }^{a}$ Wilcoxon Mann-Whitney test.

b Fisher's exact test.

${ }^{c}$ chi-squared test.

Table 2. Blood Analyses in the Participants Prior to and Following the Intervention

\begin{tabular}{|c|c|c|c|}
\hline \multirow{2}{*}{ Variable } & \multicolumn{2}{|c|}{ Result by Study Group } & \multirow{2}{*}{ P Value } \\
\hline & Intervention & Control & \\
\hline \multicolumn{4}{|l|}{$\mathrm{WBC}, \mathrm{mL}^{-1}$} \\
\hline Baseline & $13292.00 \pm 12991.27$ & $12868.00 \pm 12991.27$ & $0.352^{\mathrm{a}}$ \\
\hline 3 days & $13233.33 \pm 8244.03$ & $7400.00 \pm 6766.03$ & $0.001^{\mathrm{a}}$ \\
\hline Difference & $-404.17 \pm 11132.54$ & $-5612.50 \pm 13282.59$ & $0.016^{\mathrm{a}}$ \\
\hline \multicolumn{4}{|l|}{ hs-CRP, mg/L } \\
\hline Baseline & $4.24 \pm 7.60$ & $1.72 \pm 2.17$ & $0.024^{\mathrm{a}}$ \\
\hline 3 days & $6.98 \pm 7.43$ & $5.77 \pm 9.16$ & $0.105^{\mathrm{a}}$ \\
\hline Difference & $2.69 \pm 8.42$ & $4.03 \pm 9.43$ & $0.606^{\mathrm{a}}$ \\
\hline \multicolumn{4}{|l|}{ ANC, mL $^{-1}$} \\
\hline Baseline & $5610.28 \pm 2984.48$ & $5518.48 \pm 5610.28$ & $0.148^{\mathrm{a}}$ \\
\hline 3 days & $6952.08 \pm 5518.79$ & $2984.48 \pm 3158.71$ & $0.010^{\mathrm{a}}$ \\
\hline Difference & $779.17 \pm 5418.47$ & $-2174.96 \pm 4853.27$ & $0.261^{\mathrm{a}}$ \\
\hline \multicolumn{4}{|c|}{ Immature/total neutrophils } \\
\hline Baseline & $0.136 \pm 0.16$ & $0.136 \pm 0.17$ & $0.993^{\mathrm{b}}$ \\
\hline 3 days & $0.138 \pm 0.18$ & $0.134 \pm 0.14$ & $0.345^{\mathrm{b}}$ \\
\hline Difference & $0.003 \pm 0.26$ & $-0.002 \pm 0.19$ & $0.476^{\mathrm{b}}$ \\
\hline
\end{tabular}

Abbreviations: ANC, absolute neutrophil; hs-CRP, high-sensitivity C-reactive protein; WBC, white blood cell.

${ }^{\text {a }}$ Wilcoxon Mann-Whitney test.

${ }^{\mathrm{b}} t$ test.

vention group, however, It was not statistically significant $(\mathrm{P}=0.476)$. regarding the effect of rhG-CSF administration on the clinical parameters, it was observed that more than $90 \%$ 
of the patients who exposed to either rhG-CSF or placebo, were hospitalized for over 3 days and no significant difference was reported in the duration of hospital stay between the two groups $(\mathrm{P}=0.946)$. The mean period of hospital stay of the patients treated with rhG-CSF and placebo was $16 \pm 10$ days (range: 2.0 - 38 days) and $17 \pm 14$ days (range: 0 - 54 days), respectively. In each group, one participant $(4.0 \%)$ died during hospitalization. In the intervention group, $12.0 \%(n=3), 16.0 \%(n=4), 16.0 \%(n=4), 8.0 \%$ $(n=2)$, and $8.0 \%(n=2)$ had respiratory, hematologic, gastrointestinal, central nervous system, and cardiovascular adverse effects, respectively. The controls shared a slightly different adverse effect profile (respiratory $(n=3,12.0 \%)$, hematologic ( $n=2,8.0 \%)$, gastrointestinal $(n=6,24.0 \%)$, central nervous system ( $\mathrm{n}=1,4.0 \%)$, and cardiovascular ( $\mathrm{n}$ $=5,20.0 \%)$ ). Also, two patients $(n=2,8.0 \%)$ developed nosocomial infection in the control group.

\section{Discussion}

The positive contribution of rhG-CSF to neonatal sepsis as well as neutropenia has been studied in various studies $(30,38-40)$. In this study, it was indicated that rhGCSF was associated with considerable improvements in the number of WBC and ANC, while no significant changes were observed in the serum level of hs-CRP and immature/total neutrophil ratio. In addition, mortality rate and duration of hospital stay were comparable between the patients who received rhG-CSF or not. In our study, the initial serum level of ANC was more than 5000 cells $\mathrm{mm}^{-3}$. An increased ANC was also reported by Kocherlakota and La Gamma in response to an intravenous infusion of rhGCSF $(10 \mu \mathrm{g} / \mathrm{kg} / \mathrm{d}$ x $3 \mathrm{~d})$, whose study included seven neonates with EONS as well as neutropenia at birth (ANC $<1500$ cells $\mathrm{mm}^{-3}$ ) (26). In consistent with our findings, Kucukoduk et al. used $5 \mu \mathrm{g} / \mathrm{kg} /$ day of intravenous rG-CSF for 3 days, and indicated a significant increase in ANC meanwhile no change was observed in immature/total neutrophil ratios. They recorded the shortened length of time on the NICU in the treated infants (27). Moreover, Miura et al. corroborated the increased level of neutrophil counts in premature neonates with EONS who were exposed to $10 \mu \mathrm{g} / \mathrm{kg} /$ day of intravenous rG-CSF for 3 days. They had as mortality rate as the controls. The use of rG-CSF declined nosocomial infections over the subsequent 2 weeks (28). Likewise, Aktas et al. showed that treatment with rhG-CSF (10 $\mu \mathrm{g} / \mathrm{kg} /$ day; 1 - 4 days, median, 2 days) was associated with an outstanding recovery of the ANC in neutropenic $\left(\right.$ ANC $\left.<1.0 \times 10^{9} / \mathrm{L}\right)$ preterm infants with sepsis and short-term mortality remained unchanged in their study (38). In the study conducted by Borjianyazdi et al. in Iran, the effectiveness of G-CSF (10 $\mu \mathrm{g} / \mathrm{kg}$ for up to 5 consecutive days) was evaluated clinically in preterm infants with sepsis and neutropenia (ANC $\leq 5000 / \mu \mathrm{L}$ ). In line with our mortality rates, only one death was reported in the treated group. Furthermore, no positive results for cultures were observed. In both treated and control groups, a number of patients experienced respiratory side effects. The only significant difference between the two groups was related to length of hospitalization, in which our study failed to demonstrate a statistically significant reduction (39). In this regard, Ahmad et al. established a significant elevation of ANC meanwhile an unchanged rate of mortality or morbidity in symptomatic, septic premature neonates receiving the rG-CSF administration $(5 \mu \mathrm{g} / \mathrm{kg} /$ dose i.v. twice a day for a maximum of 7 days) (29).

There were two trials presenting a significantly more rapid rise in ANC as well as significantly fewer deaths in the rhG-CSF group. Both studies used a similar dose of rhGCSF $(10 \mu \mathrm{g} / \mathrm{kg} /$ day $)$ for preterm infants with sepsis and neutropenia (ANC $<5000$ cells $\mathrm{mm}^{-3}$ ). However, there were some methodological differences between the two studies (e.g., birthweight, administration duration, GA) (41, 42). Interestingly, Chaudhuri et al. documented these two findings for sepsis preterm infants with ANC $<1500$ cells $\mathrm{mm}^{-3}$ associated with a very high risk of mortality. Length of NICU stay was reduced significantly in the G-CSF group, as well. In their study, G-CSF was administered intravenously in a single daily dose of $10 \mu \mathrm{g} / \mathrm{kg} /$ day in a $5 \%$ dextrose solution over 20 - 40 minutes for three consecutive days (30). Although Schibler et al. did not observe a substantial difference in ANC between the treated ( $10 \mu \mathrm{g} / \mathrm{kg} / \mathrm{d}$ for 3 days) and control groups with neutropenia (ANC: G-CSF group $1698 \pm 2167$ cells $/ \mu \mathrm{L}$, placebo group $1249 \pm 877$ cells $/ \mu \mathrm{L})$ and EONS, other findings such as morbidity, mortality, and immature to total neutrophil ratio were significantly different (43). By contrast, Teng et al. in a study on very-low-birthweight infants with early neutropenia (ANC $<1500$ cells $\mathrm{mm}^{-3}$ ) demonstrated that the rhG-CSF administration (5 $10 \mu \mathrm{g} / \mathrm{kg} /$ day for 3 - 5 days) failed not only to prevent nosocomial infections but also to affect mortality and morbidity rates (40).

Carr et al. performed a meta-analysis to exhibit the safety and efficacy of G-CSF and granulocyte-macrophageCSF infusion to manage or treat mortality amongst patients suffered from suspected or proven systemic infections. They noted that the use of medical regimen, including rhG-CSF did not decrease the immediate mortality in preterm infants presented with suspected systemic infection. Moreover, there was no survival advantage following two weeks on such treatment. However, mortality was significantly improved as a result of this treatment on patients who had both systemic infection and neutropenia (44). This may justify the effects of rhG-CSF 
on mortality rate and adverse effects in our study. Indeed, myeloid lineage colony stimulating factors (CSFs) such as granulocyte-macrophage CSF (GM-CSF; CSF-2) and granulocyte CSF (G-CSF; CSF-3) are able to activate the innate immune response, ameliorate myelopoiesis, and repress apoptosis (45). The removal of apoptotic cells plays a central role in resolving inflammation and the phagocytosis of apoptotic granulocytes reduces in neonates similar to adults (46). Small neutrophil pool is quickly depleted in infants if sepsis occurs, which leads to neutropenia, while Gram-negative sepsis is recovered somehow through the G-CSF use in preterm infants $(47,48)$. Considering these data, the administration of G-CSF is suitable for management of infections in infants (49-52). This can partially arise from a hyporesponsiveness of neonatal granulocytes to G-CSF associated with anti-apoptotic effects in comparison to adults (53). However, it has been emphasized that G-CSF or GM-CSF can be effective for preterm infants with moderate $(<1700 / \mu \mathrm{L})$ or severe $(<500 / \mu \mathrm{L})$ neutropenia and systemic infection, respectively (50). In this regard, optimal timing of administration as well as monitoring of Gor GM-CSF levels are expected to maximize their positive contributions to these neonates (52).

This study has several limitations; including, sample size was low because there were some parents unwilling to continue participation during the follow-up period after discharge. Consequently, some complications related to the treatment failed to be recorded.

In conclusion, the administration of rhG-CSF was effective in a rapid increase of WBC and ANC. Furthermore, it caused an inconsiderable enhancement in the plasma concentration of hs-CRP and the cell ratio of immature/total. However, it did not affect mortality rate, adverse effects, and duration of hospital stay in the treated group. Since the present evidence is conflicting about the use of rhG-CSF for infants with sepsis; therefore, further investigations are required with larger sample size and more prolonged follow-ups.

\section{Footnotes}

\section{Clinical Trial Registration: IRCT code: IRCT20190109042311N1.}

Conflict of Interests: There is no conflict of interest in this study.

Ethical Considerations: This randomized controlled trial was designed to investigate the impact of rhG-CSF on preterm infants with EONS within a period of three days. This interventional study received approval ethical from Medical Research Ethics Committee, Mashhad University of Medical Sciences (Ethical code: IR.MUMS.REC.1389.100).
The CONSORT guidelines were adopted to design the present study, as well.

Funding/Support: This study has received financial support from the Mashhad University of Medical Sciences.

\section{References}

1. Ng PC. Diagnostic markers of infection in neonates. Arch Dis Child Fetal Neonatal Ed. 2004;89(3):F229-35. doi: 10.1136/adc.2002.023838. [PubMed: 15102726]. [PubMed Central: PMC1721679].

2. Bryce J, Boschi-Pinto C, Shibuya K, Black RE; W H O Child Health Epidemiology Reference Group. WHO estimates of the causes of death in children. Lancet. 2005;365(9465):1147-52. doi: 10.1016/S01406736(05)71877-8. [PubMed: 15794969].

3. Liu L, Johnson HL, Cousens S, Perin J, Scott S, Lawn JE, et al. Global, regional, and national causes of child mortality: An updated systematic analysis for 2010 with time trends since 2000. Lancet. 2012;379(9832):2151-61. doi: 10.1016/S0140-6736(12)60560-1. [PubMed: 22579125].

4. Gebremedhin D, Berhe H, Gebrekirstos K. Risk factors for neonatal sepsis in public hospitals of Mekelle city, north Ethiopia, 2015: Unmatched case control study. PLoS One. 2016;11(5). e0154798. doi: 10.1371/journal.pone.0154798. [PubMed: 27163290]. [PubMed Central: PMC4862626].

5. Verani JR, McGee L, Schrag SJ; Division of Bacterial Diseases, National Center for Immunization and Respiratory Diseases. Prevention of perinatal group B streptococcal disease: Revised guidelines from CDC, 2010. Recommendations and reports. 2010. Report No.: RR10. 31 p.

6. Jefferies AL. Management of term infants at increased risk for early-onset bacterial sepsis. Paediatr Child Health. 2017;22(4):223-8. doi: 10.1093/pch/pxx023. [PubMed: 29480905]. [PubMed Central: PMC5804707].

7. Hornik CP, Fort P, Clark RH, Watt K, Benjamin DK, Smith PB, et al. Early and late onset sepsis in very-low-birth-weight infants from a large group of neonatal intensive care units. Early Hum Dev. 2012;88:S69-74. doi: 10.1016/s0378-3782(12)70019-1. [PubMed: 22633519]. [PubMed Central: PMC3513766].

8. Simonsen KA, Anderson-Berry AL, Delair SF, Davies HD. Earlyonset neonatal sepsis. Clin Microbiol Rev. 2014;27(1):21-47. doi: 10.1128/CMR.00031-13. [PubMed: 24396135]. [PubMed Central: PMC3910904].

9. Amponsah SK, Adjei GO, Sulley AM, Woode J, Lindholm JA, EnweronuLaryea C. Diagnostic utility of procalcitonin versus C-reactive protein as markers for early-onset neonatal sepsis at Korle-Bu Teaching Hospital. Pan Africa Med J. 2017;27. doi: 10.11604/pamj.2017.27.142.12209.

10. Maternal-Infant Care Research Center. The Canadian neonatal network. Toronto, Ontario; 2013.

11. Weston EJ, Pondo T, Lewis MM, Martell-Cleary P, Morin C, Jewell $\mathrm{B}$, et al. The burden of invasive early-onset neonatal sepsis in the United States, 2005-2008. Pediatr Infect Dis J. 2011;30(11):937-41. doi: 10.1097/INF.0b013e318223bad2. [PubMed: 21654548]. [PubMed Central: PMC3193564].

12. Stoll BJ. Early-onset neonatal sepsis: A continuing problem in need of novel prevention strategies. Pediatrics. 2016;138(6). doi: 10.1542/peds.2016-3038. [PubMed: 27940736].

13. Money D, Allen VM, Yudin MH, Allen VM, Bouchard C, Boucher M, et al. The prevention of early-onset neonatal group B streptococcal disease. J Obstetrics Gyn Can. 2013;35(10):939-48. doi: 10.1016/s17012163(15)30818-5.

14. Lim WH, Lien R, Huang YC, Chiang MC, Fu RH, Chu SM, et al. Prevalence and pathogen distribution of neonatal sepsis among very-low-birth-weight infants. Pediatr Neonatol.2012;53(4):228-34. doi: 10.1016/j.pedneo.2012.06.003. [PubMed: 22964280]. 
15. Hengst JM. The role of C-reactive protein in the evaluation and management of infants with suspected sepsis. Adv Neonatal Care. 2003;3(1):3-13. [PubMed: 12882177].

16. Ali AM, Moaz MA, Ghoniem E, Abd El Motaleb T, Sheri N. Reliability of serum procalcitonin concentrations for the diagnosis of sepsis in neonates. Egypt J Immunol. 2008;15(1):75-84. [PubMed: 20306671].

17. Nuntnarumit P, Pinkaew $O$, Kitiwanwanich $S$. Predictive values of serial C-reactive protein in neonatal sepsis. J Med Assoc Thai. 2002;85 Suppl 4:S1151-8. [PubMed: 12549789].

18. Benitz WE, Han MY, Madan A, Ramachandra P. Serial serum Creactive protein levels in the diagnosis of neonatal infection. Pediatrics.1998;102(4). E41. doi: 10.1542/peds.102.4.e41. [PubMed: 9755278].

19. Jankovic B, Pasic S, Markovic M, Veljkovic D, Milicic M. [C-reactive protein concentrations during initial (empiric) treatment of neonatal sepsis]. Srp Arh Celok Lek. 2001;129 Suppl 1:17-22. Serbian. [PubMed: 15637985].

20. Pulliam PN, Attia MW, Cronan KM. C-reactive protein in febrile children 1 to 36 months of age with clinically undetectable serious bacterial infection. Pediatrics. 2001;108(6):1275-9. doi: 10.1542/peds.108.6.1275. [PubMed: 11731648].

21. Ng PC, Cheng SH, Chui KM, Fok TF, Wong MY, Wong W, et al. Diagnosis of late onset neonatal sepsis with cytokines, adhesion molecule, and C-reactive protein in preterm very low birthweight infants. Arch Dis Child Fetal Neonatal Ed. 1997;77(3):F221-7. doi: 10.1136/fn.77.3.F221. [PubMed: 9462194]. [PubMed Central: PMC1720722].

22. Mishra UK, Jacobs SE, Doyle LW, Garland SM. Newer approaches to the diagnosis of early onset neonatal sepsis. Arch Dis Child Fetal Neonatal Ed. 2006;91(3):F208-12. doi: 10.1136/adc.2004.064188. [PubMed: 16632649]. [PubMed Central: PMC2672708].

23. Ng PC, Lam HS. Diagnostic markers for neonatal sepsis. Curr Opin Pediatr. 2006;18(2):125-31. doi: 10.1097/01.mop.0000193293.87022.4c. [PubMed:16601490].

24. Horisberger T, Harbarth S, Nadal D, Baenziger O, Fischer JE. G-CSF and IL-8 for early diagnosis of sepsis in neonates and critically ill children - safety and cost effectiveness of a new laboratory prediction model: Study protocol of a randomized controlled trial [ISRCTN91123847]. Crit Care. 2004;8(6):R443-50. doi: 10.1186/cc2971. [PubMed: 15566590]. [PubMed Central: PMC1065067].

25. Hopkins SJ, McMahon CJ, Singh N, Galea J, Hoadley M, Scarth S, et al. Cerebrospinal fluid and plasma cytokines after subarachnoid haemorrhage: CSF interleukin-6 may be an early marker of infection. $J$ Neuroinflammation. 2012;9:255. doi: 10.1186/1742-2094-9-255. [PubMed: 23176037]. [PubMed Central: PMC3526412].

26. Kocherlakota P, La Gamma EF. Human granulocyte colonystimulating factor may improve outcome attributable to neonatal sepsis complicated by neutropenia. Pediatrics. 1997;100(1). E6. doi: 10.1186/1742-2094-9-255. [PubMed: 9200380].

27. Kucukoduk S, Sezer T, Yildiran A, Albayrak D. Randomized, doubleblinded, placebo-controlled trial of early administration of recombinant human granulocyte colony-stimulating factor to non-neutropenic preterm newborns between 33 and 36 weeks with presumed sepsis. Scand J Infect Dis. 2002;34(12):893-7. doi: 10.1080/0036554021000026966. [PubMed: 12587621].

28. Miura E, Procianoy RS, Bittar C, Miura CS, Miura MS, Mello C, et al. A randomized, double-masked, placebo-controlled trial of recombinant granulocyte colony-stimulating factor administration to preterm infants with the clinical diagnosis of early-onset sepsis. Pediatrics. 2001;107(1):30-5. doi:10.1542/peds.107.1.30. [PubMed: 11134430].

29. Ahmad A, Laborada G, Bussel J, Nesin M. Comparison of recombinant granulocyte colony-stimulating factor, recombinant human granulocyte-macrophage colony-stimulating factor and placebo for treatment of septic preterm infants. Pediatr Infect Dis J. 2002;21(11):1061-5. doi: 10.1097/01.inf.0000036091.75362.b9. [PubMed: 12442030].

30. Chaudhuri J, Mitra S, Mukhopadhyay D, Chakraborty S, Chatterjee S. Granulocyte colony-stimulating factor for preterms with sepsis and neutropenia: A randomized controlled trial. J Clin Neonatol. 2012;1(4):202-6. doi: 10.4103/2249-4847.105993. [PubMed: 24027727]. [PubMed Central: PMC3762052]

31. Hollingshead LM, Goa KL. Recombinant granulocyte colonystimulating factor (rG-CSF). A review of its pharmacological properties and prospective role in neutropenic conditions. Drugs. 1991;42(2):300-30. doi: 10.2165/00003495-199142020-00009. [PubMed: 1717226].

32. Lee JA, Sauer B, Tuminski W, Cheong J, Fitz-Henley J2, Mayers M, et al. Effectiveness of granulocyte colony-stimulating factor in hospitalized infants with neutropenia. Am J Perinatol. 2017;34(5):458-64. doi: 10.1055/s-0036-1593349. [PubMed: 27649291]. [PubMed Central: PMC5359073].

33. Schrag SJ, Farley MM, Petit S, Reingold A, Weston EJ, Pondo T, et al. Epidemiology of invasive early-onset neonatal sepsis, 2005 to 2014. Pediatrics. 2016;138(6). doi: 10.1542/peds.2016-2013. [PubMed: 27940705].

34. Zea-Vera A, Ochoa TJ. Challenges in the diagnosis and management of neonatal sepsis. J Trop Pediatr. 2015;61(1):1-13. doi: 10.1093/tropej/fmu079. [PubMed: 25604489]. [PubMed Central: PMC4375388]

35. Willfort A, Lorber C, Kapiotis S, Sertl S, Hainz R, Kirchweger P, et al. Treatment of drug-induced agranulocytosis with recombinant granulocyte colony-stimulating factor (rh G-CSF). Ann Hematol. 1993;66(5):241-4. doi: 10.1007/BF01738472. [PubMed: 7685193].

36. Newgard CD, Fleischman R, Choo E, Ma OJ, Hedges JR, McConnell KJ. Validation of length of hospital stay as a surrogate measure for injury severity and resource use among injury survivors. Acad Emerg Med. 2010;17(2):142-50. doi: 10.1111/j.1553-2712.2009.00647.x. [PubMed: 20370743]. [PubMed Central: PMC4715859].

37. WHO. Perinatal mortality: A listing of available information. Geneva: WHO, Family and Reproductive Health; 1996.

38. Aktas D, Demirel B, Gursoy T, Ovali F. A randomized case-controlled study of recombinant human granulocyte colony stimulating factor for the treatment of sepsis in preterm neutropenic infants. Pediatr Neonatol. 2015;56(3):171-5. doi: 10.1016/j.pedneo.2014.06.007. [PubMed: 25458637].

39. Borjianyazdi L, Froomandi M, Noori Shadkam M, Hashemi A, Fallah R. The effect of granulocyte colony stimulating factor administration on preterm infant with neutropenia and clinical sepsis: A randomized clinical trial. Iran J Ped Hematol Oncol. 2013;3(2):64-8. [PubMed: 24575272]. [PubMed Central: PMC3915446].

40. Teng RJ, Wu TJ, Sharma R, Garrison RD, Hudak ML. Efficacy of recombinant human granulocyte colony stimulating factor in verylow-birth-weight infants with early neutropenia. J Formos Med Assoc. 2015;114(2):174-9. doi: 10.1016/j.jfma.2012.10.009. [PubMed: 25678180].

41. Gathwala G, Walia M, Bala H, Singh S. Recombinant human granulocyte colony-stimulating factor in preterm neonates with sepsis and relative neutropenia: A randomized, single-blind, non-placebo-controlled trial. J Trop Pediatr. 2012;58(1):12-8. doi: 10.1093/tropej/fmr012. [PubMed: 21296862].

42. Bedford Russell AR, Emmerson AJ, Wilkinson N, Chant T, Sweet DG, Halliday HL, et al. A trial of recombinant human granulocyte colony stimulating factor for the treatment of very low birthweight infants with presumed sepsis and neutropenia. Arch Dis Child Fetal Neonatal Ed. 2001;84(3):F172-6. doi: 10.1136/fn.84.3.F172. [PubMed: 11320043]. [PubMed Central: PMC1721238].

43. Schibler KR, Osborne KA, Leung LY, Le TV, Baker SI, Thompson DD. A randomized, placebo-controlled trial of granulocyte colonystimulating factor administration to newborn infants with neutropenia and clinical signs of early-onset sepsis. Pediatrics. 1998;102(1 Pt 1):6-13. doi: 10.1542/peds.102.1.6. [PubMed: 9651406].

44. Carr R, Modi N, Doré CJ. G-CSF and GM-CSF for treating or preventing neonatal infections. Cochrane Database Sys Rev. 2003;(3).

45. Mathias B, Szpila BE, Moore FA, Efron PA, Moldawer LL. A review of GM-CSF therapy in sepsis. Medicine (Baltimore). 2015;94(50). e2044. 
doi: 10.1097/MD.0000000000002044. [PubMed: 26683913]. [PubMed Central: PMC5058885].

46. Gille C, Steffen F, Lauber K, Keppeler H, Leiber A, Spring B, et al. Clearance of apoptotic neutrophils is diminished in cord blood monocytes and does not lead to reduced IL-8 production. Pediatr Res. 2009;66(5):507-12. doi: 10.1203/PDR.0b013e3181b9b470. [PubMed: 19668110].

47. Christensen RD, Rothstein G. Exhaustion of mature marrow neutrophils in neonates with sepsis. J Pediatr. 1980;96(2):316-8. doi: 10.1016/S0022-3476(80)80837-7. [PubMed: 6985958].

48. Melvan JN, Bagby GJ, Welsh DA, Nelson S, Zhang P. Neonatal sepsis and neutrophil insufficiencies. Int Rev Immunol. 2010;29(3):315-48. doi: 10.3109/08830181003792803. [PubMed: 20521927]. [PubMed Central: PMC3103186].

49. Bo L, Wang F, Zhu J, Li J, Deng X. Granulocyte-colony stimulating factor (G-CSF) and granulocyte-macrophage colony stimulating factor (GM-CSF) for sepsis: A meta-analysis. Crit Care. 2011;15(1):R58. doi: 10.1186/cc10031. [PubMed: 21310070]. [PubMed Central: PMC3221991].

50. Castagnola E, Dufour C. Role of G-CSF GM-CSF in the management of infections in preterm newborns: An update. Early Hum Dev. 2014;90 Suppl 2:S15-7. doi: 10.1016/S0378-3782(14)50005-9. [PubMed: 25220119].

51. Kale A, Bonde V. Neonatal sepsis: An update. Iran J Neonatology IJN. 2014;4(4):39-51.

52. Schuller SS, Kramer BW, Villamor E, Spittler A, Berger A, Levy O. Immunomodulation to prevent or treat neonatal sepsis: Past, present, and future. Front Pediatr. 2018;6:199. doi: 10.3389/fped.2018.00199. [PubMed: 30073156]. [PubMed Central: PMC6060673].

53. Molloy EJ, O'Neill AJ, Grantham JJ, Sheridan-Pereira M, Fitzpatrick JM, Webb DW, et al. Granulocyte colony-stimulating factor and granulocyte-macrophage colony-stimulating factor have differential effects on neonatal and adult neutrophil survival and function. Pediatr Res. 2005;57(6):806-12. doi: 10.1203/01.PDR.0000156500.13600.B5. [PubMed: 15718363]. 